\title{
LEARNING DISABILITY AND SPEECH DISORDER AMONG TODDLERS: A CASE STUDY ON KURDISH PRE-SCHOOL CHILDREN
}

\author{
Areen Ahmed Muhammed \\ Charmo University, College of Education and Languages, English Department, \\ Chamchamal, Iraq \\ E-mail: areen.muhammed@charmouniversity.org
}

Received: 26 September 2019

Accepted: 05 November 2019

\begin{abstract}
For decades, scholars and linguists in Iraqi Kurdistan studied on University students. However, a few types of research could be found in the area of language disability among Kurdish children. This research tried to clarify and illustrate the impact of those factors that have the main role in enhancing children and evoke them while they are in the phase of learning to talk. It also tried to show disorders as infants have, and to find out the most effective factor, which helps infants to learn to talk soon. The participants in this research were teachers at two different primary schools in Sulaymaniya. Moreover, two methods of data collection were used in this study (questionnaire and interview). Additionally, thirty teachers took part in the questionnaire; additionally, fifteen teachers took part in the demographic section and three mothers in the interview section. The finding of this research showed that toddlers had positive views about the effect of reading stories by their parents. They found that it was helpful for toddlers. In addition, the effectiveness of parents' role on children's talking was found out in this research. On the other hand, the impact of genders on infants was also carried out in this study. The most important finding of this research was the effectiveness of telling the original names of items to infants by their parents. In addition, mothers could positively enhance the children's ability to talk and learn sooner than those whose parents did not talk to them much or they had quiet parents.
\end{abstract}

Keywords: language disability, speech disorder, Kurdish toddlers, language acquisition.

\section{Introduction}

Learning to talk is one of the most wonderful things that children start to learn in their early ages. Crying and mumbling stage is the giant step that shows the process of the child's growth in its ability to speak and understand the others. In addition, expressing the feeling and trying to communicate at different stages are other processes that evoke a child's ability to talk. Learning to talk seems easy for most children, but for some children, they must struggle to acquire the language. In other words, learning to talk is based on children's environment and the circumstance they grow in; this means that if their parents speak with them, then they will learn to talk sooner; otherwise, they need more time and must struggle to learn how to talk. (Edwards, et al. 2013) cited in learningtotalk@comids.wise.edu). 
Regarding the problem of the current paper, the problems that children face in learning to talk is the way they produce sound, pronounce the words, and the vocabulary they have to acquire; for example, reading stories or telling infants the original names of things around them will solve this problem. Later, it shows how parents can have an effect on children in learning to speak.

Furthermore, the paper aims at revealing a hypothesis that reading stories to children by their parents helps them learn to talk and increases their vocabulary. In the process of language teaching, it is the job of the language teacher to help the students learn by encouraging them to speak, explaining the rules, and correcting the mistakes of the students. This paper attempts to explain several ambiguous questions as to "Why some children do not learn their language soon?" "Does reading a story for children by their parents help them to learn and talk?" "Does reading a story in another language can help them to learn the designated language?" "Can those children who have language disability learn a language in the same way as the normal ones?" "Does the teacher's treatment have effects on the students?" or "Do a huge number of children in a family affect the parents to neglect some of them?" Additionally, this study aims at finding out the positive and negative impacts of reading stories for children. The researcher's hypothesis is that reading stories to children by their parents helps them learn to talk and increases their vocabulary. The main questions that this research attempts to answer are:

1. Do infants who have professional parents talk much more than those whose parents are not professional?

2. Could telling infants the origin of the names of things around them be a way to reduce their disorder?

3. Do girls learn to talk sooner than boys do?

The setting of this research is in the primary schools in Sulaymaniya. The questionnaire and demographic section have been done in three different schools (FaqeQadr, SpiHasar, and Sulaymaniya). Among the teachers who are all Kurdish, they all have sufficient experiences in language teaching to children.

\section{Literature Review}

\subsection{Educational Background}

One remarkable idea about how children all over the world learn to talk is the high degree of similarity in the early age of learning the language. This means that there is a similarity between children in regards to how they acquire a language. Previous researchers have described it in many aspects. In this research, the researcher shows the others' opinions on the characteristics of language learning. Hart and Riseley (1995) made a survey of families who are employed and unemployed. They found that employed parents talk more to their children than unemployed ones. This is due to the fact that employed parents spend more times of the day far from their children and when they return home they ask their children about their activities they have done that day; hence, the parents are enhancing them to talk and describe the day that their children spent, which improves their speech. In contrast to unemployed parents who spend most of their time to stay at home, they tend to avoid speaking to their children as they count it as a headache.

In another source, Ocher (1999) says that the person who has daily life interaction with children is the infant's mother, whose behaviour characterizes children's language. As it is obvious that the mother is very close to her children so that they can be described as a mirror of their mothers. Furthermore, Brown (1973) dictates that whenever the parents 
teach their children a new item they should teach the infants the original name and teach them with the child's language. For example, when they have stomach-ache they should tell them it is stomach, not "tummy" (as the child's interpretation in the language). Additionally, it is mentioned by an American psychologist, Bruner $(1983,1996)$ who stresses the role of parents and teachers in helping their toddlers concerning how to acquire the language fluently. He believes that both parents and teachers can develop and encourage language learning for children.

According to some other linguists such as Chomsky, he says, "we are designed to walk, we are not taught; likewise for language, one cannot prevent a child from acquiring language." He means that human learns to walk without someone who teaches him/her; similarly, learning language has the same procedure; no one can stop a child from learning a language (Chomsky, 1994). As an explanation to the above quotation; children systematically ignore those attempts when their parents correct them; for instance, using "jijamas" instead of "pyjamas". As the effect, it does not matter how often the parents correct them, still, children will follow the procedure that they desire to learn on; which means that children mostly do not imitate their parents' speech. In contrast, they ignore parents' speech when parents keep correcting them repetitively. Even when children want to imitate what they hear; they are unable to produce well since their language system is not completed yet and it is not fully functional. Additionally, it is not his/her concern no matter how many times you correct him/her, since s/he likes "jijamas" then s/he will keep repeating the same word, because according to his/her point of view that word is correct and functional. Another chunk like "my pencil" for "my crayons" or "two-foot" for "feet" shows that children do not imitate adult's speech. (Schumacher and Deshler, 2009).

By contrast, Pinker $(1994,1999)$ says that in common sense of theory; children listen to parents and imitate them. He illustrates that children repeat what their parents say and it is the parents' duty to help their children to explain things which they do not understand. It is the parents' task to encourage them, help them speak, and correct their errors. In another study by De Villiers (2007), through his experiment, it shows that he does not believe in the claim that children acquire things about language systematically and arbitrarily. Learning a language is not the result of imitation as children can express language that they have never been explicitly taught before. The researcher admits that he has the same idea as Chomsky, who says that children do not learn by imitation. They can acquire language without being taught.

Furthermore, Brumfit $(1980,1984)$ and other linguists mention those younger children (toddlers) like to listen storytelling especially when their parents read the stories for them; whilst, elder children start to read stories for themselves because the language of the story is more attractive than both pictures and games. On the other hand, reading foreign stories for children helps them to learn another language easily. In addition, the most effective result in teaching is to show pictures and read stories together as it has been concluded (Brumfit et al, 1991 cited in Kennedy and Jarvis, 1991). To conclude, every child has an ability to communicate, as infants, children babble, coo, and cry, vocally or none vocally send some messages and receives many others at the same time. At the end of their first year, they are trying to imitate the words and sounds that they hear around them. At the age of eighteen months, children produce their first words and then try to make sentences such as "bye daddy" or "mommy sock" (Clark, 2003). 
Learning Disability and Speech Disorder among Toddlers: A Case Study on Kurdish Pre-School Children, Areen Ahmed Muhammed

\subsection{Previous Studies}

As illustrated previously, reading stories can help many children to avoid disorder. On the idea of the effect of reading stories for children, a national survey in an American kindergarten class in (1998-1999) shows that parents who told stories to their kindergarten children three or more times a week had their children with better language skills and capacity than those who did so less than three times a week (National centre for education statistics, 2000). The idea describes that those families who read stories (children stories) more to their children then the books give a better opportunity to have more vocabulary. When the family reads the same story twice, then the child hears those vocabularies twice; consequently, they can recognize the words easily and pick them up faster.

In a study on eight-month-old infants, Jusczyk and Honne gave the chance to the children to listen to a recorded story, which contained unusual words. After two weeks, the researchers tested the children with two lists of words; one taken from the story and the other was a list of new words that did not exist in the story. They noticed that the infants were more familiar and got the words that existed in the story easier than the new words (Jusczyk and Honne, 1996). Another study by Levin and Vevea (1998) who made a conversation between 22 toddlers and their mothers, shows that the infants were between (16-22) months of age. The researchers found that those children whom their mothers talk more, then they have more vocabulary knowledge than those who have more quiet mothers. Additionally, on August 23, 2011, psychologists in the University of Liverpool found that two-year-old children could understand complex grammar before learning to talk in full sentences. The study also shows that infants know more about language structures that they can produce, and they might use the structure of sentences to understand new words. The same study has suggested that children between the ages of two and three begin to make their understanding of grammar gradually from watching and listening to people.

Further researches have been made on April 10, 2013; the new study from the University of Pennsylvania shows that the two-year-old children can understand basic grammar rules when they first learn to talk. Similarly, on January 11, 2012, researchers discovered that children under the age of two could use different strategies than previously thought. During the study at Queen's University, the researchers changed the vowel sounds that the participants heard over headphones as they spoke, they noticed that the adults and young children can change their vowel sounds but the toddlers cannot. Moreover, on June 14,2013 , the sound of infants was considered cute when they learned to talk, but not particularly elaborated. However, the papers by Newcastle University experts have shown that toddlers' speech is far more advanced than previously understood.

Studies that were done on children who do not have their parents (mother and father or orphans) show that those toddlers face many obstacles and could not grow up socially, especially boys (Bigner, 1979). Moreover, the studies also show that those who have elder brother feel this lack less in comparison to those infants who do not have it (Smith, 1968). Additionally, studies on two-year-olds show that there is a strong connection between delayed language and aggressive behaviour, with evidence that the connection is casual and may be caused by frustration (Carson et al, 1998). Furthermore, several studies about first language acquisition have shown that girls learn the first language sooner and better than boys (Douglas, 1964; and Morris, 1966). Some other researchers have also shown that primary-aged children with a low level of reading comprehension make more improvement when they are provided with intervention to develop their oral language (Snowling et al, 2010). 


\section{Methodology}

\subsection{Research Method}

The method was based on a strong theoretical framework, which affected the development of a strong approach to the research. In the study, two methods of data collection have been used, in which they are quantitative, questionnaire, and qualitative, interview (responses to the module that have been generated from recorded, face-to-face, and individual interview). The participants' responses were analyzed to evaluate possible enhancing for their preparation to encourage them (McCashen, 2005: 48).

Using the two methods (Qualitative and Quantitative) together can help the researcher to achieve the exact numerical data, which is the main aim of the study (Cohen et al, 2007: 351). Furthermore, Dornyei (2007) describes the role of mixed methods in applied linguistics studies.

\subsubsection{Questionnaire}

A questionnaire is "any written instrument that presents respondents with a series of questions which they are selecting from and among existing answer" (Brown, 2001: 18). In the current research, the questionnaire used consisted of two sections. In the demographic section, the background information about children in learning the language is collected. It includes some information about the class environment, the effect of the second child's birth, having a large number of children in the same family, and so on. The second section consists of some problems of infants in learning to talk. It includes some problems like their health, the differences between a child's gender in learning to talk, and the role of their parents in motivating them.

The questionnaire was translated into the Kurdish language to help the participants understand the language easily and answer clearly. Before giving the questions to the respondents, an explanation was given to them about the topic of the questionnaire. Furthermore, they were also assured of anonymity. Moreover, the questionnaire contained eighteen questions; ten of them were about a child's problem and others were collecting some background information. All of them were about children, language learning, and children's problems like their health or genders and their parents at making conversation with them not much since those will bring a problem to them in speaking.

The questions, which are directed to the teachers, had four choices; they had to tick the one that they agree with the method used, followed by the Likert scale method. This paper's questionnaire was applied in three different primary schools (SpiHasar primary school, FaqeQadr primary school, and Sulaymaniya primary school). Moreover, the respondents were forty-five teachers. Respectively, fifteen teachers took part in demographic section, which is about the background information. The rest, thirty teachers, took part in section two, which is about the problems of toddlers in acquiring new language.

The four options were: "Strongly agree", "Agree", "Disagree", and "Strongly disagree". For section two; however, "Neutral" was neglected on purpose by the researcher to provide the best result and avoid confusion. In addition, some of the options were: "yes" or "no" for section one. The respondents were not asked to give their opinions about the options; instead, they were only asked to tick one of the options because it is easier and more economical for them. Moreover, the researcher collected the information within primary schools in Sulaymaniya. As Cohen and other researchers suggest, the researcher was present at the time of the questionnaire in order to explain any ambiguity or misunderstanding in 
Learning Disability and Speech Disorder among Toddlers: A Case Study on Kurdish Pre-School Children, Areen Ahmed Muhammed

the time the respondents might have difficulty with any question (Cohen and Holliday, 1979, 1982, 1996; Cohen and Manion, 1994; Cohen et al. 2004; and Cohen and Nagel, 1961).

\subsubsection{Interview}

Another method of data collection is an interview; that is, a conversation in which the interviewer gathers information from the interviewees (Richard Nordauist, 2013). In this method of data collection, the respondents feel free to express their feelings and it has an advantage for the researcher to get more knowledge about the topic. The interview consisted of five questions. The questions were simple and clear, like "Does picture story have an effect on infants' speaking?", "Do the parents treat their infants as a mature one?" and so on. The interviews were done in the interviewees' home and in public libraries to create a quiet atmosphere. This method has been done on the infant's parents $(n=3)$.

\subsubsection{Research Question}

This paper serves in answering three research questions;

1. Do infants with professional parents talk much more than those whose parents are not professional?

2. How is the idea of telling infants the original names of the stuff around them to reduce their disorder?

3. Do girls learn to talk sooner than boys?

\section{Presentation and Discussion}

This section presents and discusses the problems about how children learn to talk and the main causes of their disorders. This section divides into two parts; part one presents and includes the results and findings of the questionnaire and interview. Part 2 discusses and illustrates the data in detail, with comparisons with findings of the previous studies and literature review; the findings of the present research will be discussed in relation to each research question.

\subsection{Results and Findings}

This part contains the analysis of the research data collected from the questionnaire and the interview. Quantitative data were collected from the questionnaire survey. Moreover, qualitative data were gathered through a face-to-face interview.

\subsubsection{Questionnaire Results and Discussions}

This subpart includes the problems which infants face while they learn to talk and make contacts with their surroundings. Additionally, it explains the factors behind these problems. Moreover, it will show those factors, which reduce these obstacles. Furthermore, most of the participants $(n=25)$ strongly agreed that having a large number of children in the same family makes them lose an opportunity to talk and learn soon; and only three of the participants agreed with it. At the same time, a few $(n=2)$ of them saw that large numbers of children in a family do not have an effect on infants or toddlers in learning to talk. The result shows that the number of children in one family has many effects on child's speaking and having a few numbers of children provides a chance to talk more; the above discussion illustrated the first statement.

In addition, for the second statement, parents' field (employed and non-employed ones) may have an effect on children's talking and enhance them to learn faster and more 
appropriately; as almost half of the participants $(=18)$ agreed upon, in which $\% 60$ thought that those toddlers who have professional parents talk more than toddles who have nonprofessional parents; these findings are also found in the studies by both Hart and Riseley (1995). The survey on families, who are employed and non-employed parents, found that employed parents talk more to their children in compared to non-employed because employed families are far from their children for the most part of the day and when they return home they give more opportunity to their children to talk and discuss the day that they have passed; in contrast, fewer opportunities of talking are given to those children who have non-professional parents. Meanwhile, only a few of the participants $(n=3)$ strongly agree, while one third $(n=7)$ disagree and only a small number $(n=2)$ strongly agreed with the statement.

Concerning the third statement regarding families especially mothers in evoking their infants; toddlers are in the process of learning phase to make a conversation (talk), in which (97\%) of the participants strongly agreed with it whether to have a talkative mother or anyone else in the family that enhance them in making a conversation and only ( $3 \%$ ) agreed compared to those families which have silent (less talkative) mothers or illiterate family members. Levin and Vevea (1998) have also found this result in the study, as they found that talkative mothers would make toddlers have a lot of vocabulary compared to those infants who have quiet mothers. In addition, Hutten (1999) confirms the mother's behaviour on infants during the talking process and phase.

Concerning statement four, reading story to children by their parents will help children's ability to talk, as only $3 \%$ of the participants refused the idea; by contrast, most of the participants (73\%) strongly agreed and ( $23 \%$ ) agreed upon the idea of reading stories and books to children may help them to talk sooner. The idea can be supported by the opinion of (Brumfit et al, 1991, cited in Kennedy and Jarvis, 1991) who also think that younger children like stories especially when they are read by their parents, since they easily pick the new words, retain them as well, and enrich their vocabulary bank. Moreover, those infants whose books are read for them have a wider amount of vocabulary (have a better lexicological system) in comparison with those infants who are absent with this skill.

As for statement five, which is about telling the original names of items around toddlers may reduce their disorder; most of the participants (67\%) strongly disagreed and only $27 \%$ agreed upon the idea. A similar result can also be found in the study by Brown (1973). He dictates that when children learn the new names of items correctly, the original names rather than the forgiven names, it may reduce their disorder. Moreover, a few participants by the range of $6 \%$ stood against this finding, and they thought that toddlers would learn the original names of the items by passing of time.

\subsubsection{Interview Results and Discussions}

Three Kurdish mothers participated in this section. During the interview, participants felt free about giving their personal opinions. Moreover, the mothers were asked about their treatments with the toddlers between the ages of one to six years. Furthermore, they were also asked about the impact of picture stories on their children's language learning. Another question that was asked to the mothers was about correcting infants' mistakes or not. Later, the fourth question asked to the mothers was about their behaviours of talking or whether they encourage their toddlers or not. Finally, the last question was about the birth of new infants or having huge numbers of new-born babies in their families, whether this will make the children neglected and bring side effects on children's learning. 
The mothers were asked several questions. Firstly, one of the interviewees stated, "I mostly correct my infants' mistakes, but sometimes the mother does not wish to correct the errors of her babies for the purpose of talking in a childish way rather than the mature person". However, another mother explained that correcting infants' mistake depends on age, which means that the mistakes made by infants who are above two years old will be corrected but not those made by the younger ones. Finally, the last mother mentioned, "I do not correct my toddlers' mistakes since I see the infants' mistakes are cooler than a simple corrected version". These results as they were found in this interview stood against Hutten's (1999) opinions in which he describes children as a mirror of their mothers and the time mothers let their infants' mistakes continue then the toddlers will learn in an incorrect way and it will be fossilized.

Furthermore, the mothers were asked whether they do talk to their children a lot or not. Two of the mothers answered with "yes" and they mentioned that they talk to their infants a lot; since talking with infants will enhance them to talk soon. This result also was found in the work of Levin and Vevea (1998); who found that those children whose mothers talk more have a lot of vocabulary and talk sooner in comparison with those children who have quiet mothers. On the contrary, the third mother said "No, I do not talk much to my infants, because I do not have a lot of time...", also she thought that children will learn to talk by themselves as it is against the idea of both Leven and Vevea's findings. Meanwhile, by the support of Chomsky's (1994) opinion, who says that children will learn any language and they will talk without the help of others because it is an innate ability that every child has. The idea of the third mother cannot be rejected. Additionally, all the interviewees agreed on the effect of picture stories as they mentioned the importance of pictures on their children's language learning; as this result can be supported by the work of Brumfit et al, (1991), who illustrates that the most effective way in teaching children is to retell different picture stories or through reading picturesque books.

In another question, the interviewer asked the participants about the birth of the second child and its effect on the first child. All the mothers thought that their first child would be neglected with the birth of the second one gradually even without any intention. Additionally, they stated that surely the second child would be motivated more than the first child due to the role of too much care on the second. The idea can be confirmed through the work of Smith (1968), who said that those toddlers who have elder brother/sister would talk less and feel more anxious in comparison with those who do not have an elder brother or sister.

Finally, the last question was asked to the mothers about the background information (demographic) which was about the parents' treatments with their children in the range of 1 to 6 years as a mature one. The first mother answered the question as "I treat my child as a grown-up, and not like a child". The second interviewee stated as the first mother. In contrast, the last mother had an opposite idea regarding the question compared to the first two mothers. She answered the question as "while I start a conversation with my infant in a childish way; it gives me a fresh mood and will help my toddler to talk to me more and this encourages her".

\begin{tabular}{|l|}
\hline 1. Has a large number of children in the same family \\
\hline 2. Infants who have professional family compare to non-professional \\
\hline 3. Those parents who talk more to infants in comparison to those who ignore them \\
\hline 4. Reading story to children by their parents \\
\hline 5. Telling the original name of items \\
\hline
\end{tabular}




\begin{tabular}{|l|}
\hline 6. Girls learn to talk sooner than boys \\
\hline 7. Teacher's treatment \\
\hline 8. Social interaction affection \\
\hline 9. Family's social status (if parents got divorced) \\
\hline 10. Toddler's health \\
\hline
\end{tabular}

Table1. The Causes of Language Disability and Speech Disorder for Toddlers

\begin{tabular}{|c|c|c|c|c|c|c|c|c|}
\hline 1 & 25 & $83 \%$ & 3 & $10 \%$ & 0 & $0 \%$ & 2 & $7 \%$ \\
\hline 2 & 3 & $10 \%$ & 18 & $60 \%$ & 7 & $23 \%$ & 2 & $7 \%$ \\
\hline 3 & 29 & $97 \%$ & 1 & $3 \%$ & 0 & $0 \%$ & 0 & $0 \%$ \\
\hline 4 & 22 & $73 \%$ & 7 & $23 \%$ & 1 & $3 \%$ & 0 & $0 \%$ \\
\hline 5 & 20 & $67 \%$ & 8 & $27 \%$ & 1 & $3 \%$ & 1 & $3 \%$ \\
\hline 6 & 21 & $70 \%$ & 5 & $17 \%$ & 2 & $7 \%$ & 2 & $7 \%$ \\
\hline 7 & 23 & $77 \%$ & 5 & $17 \%$ & 1 & $3 \%$ & 1 & $3 \%$ \\
\hline 8 & 22 & $73 \%$ & 8 & $27 \%$ & 0 & $0 \%$ & 0 & $0 \%$ \\
\hline 9 & 15 & $50 \%$ & 12 & $40 \%$ & 2 & $7 \%$ & 1 & $3 \%$ \\
\hline 10 & 23 & $77 \%$ & 7 & $23 \%$ & 0 & $0 \%$ & 0 & $0 \%$ \\
\hline
\end{tabular}

Table2. Numerical Data for the Statements of the Questionnaire's Result Figure1. The Pie Chart of the Questionnaire's Statements

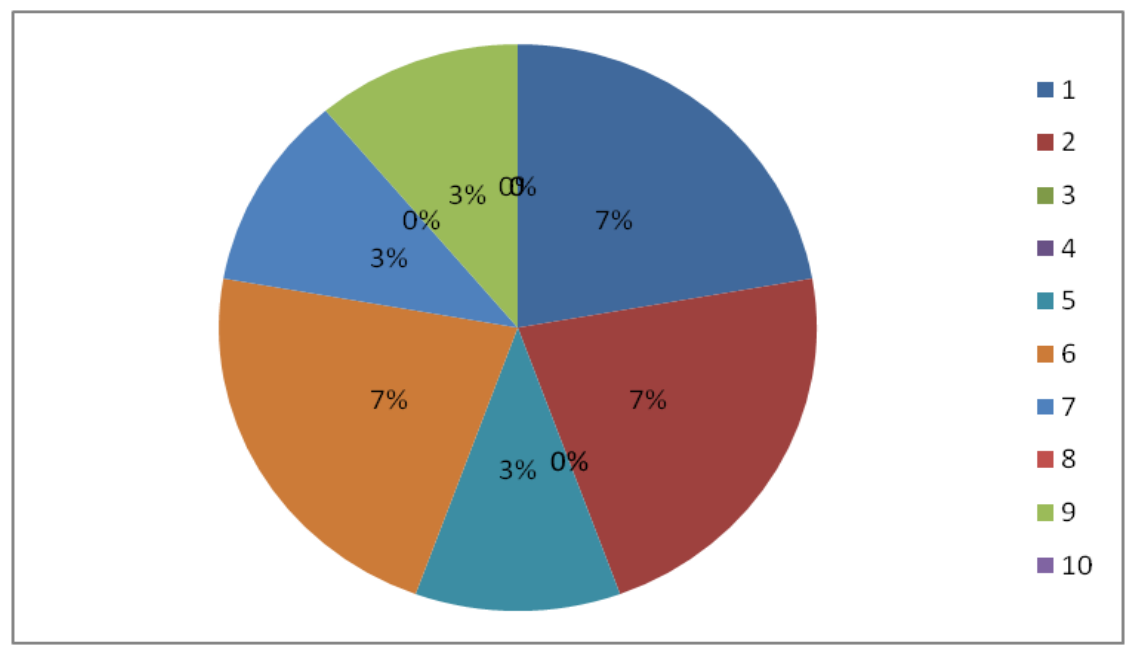

\begin{tabular}{|c|c|c|c|c|}
\hline 1 & 25 & 3 & 0 & 2 \\
\hline 2 & 3 & 18 & 7 & 2 \\
\hline 3 & 29 & 1 & 0 & 0 \\
\hline 4 & 22 & 7 & 1 & 0 \\
\hline 5 & 20 & 8 & 1 & 1 \\
\hline 6 & 21 & 5 & 2 & 2 \\
\hline 7 & 23 & 5 & 1 & 1 \\
\hline 8 & 22 & 8 & 0 & 0 \\
\hline 9 & 15 & 12 & 2 & 1 \\
\hline 10 & 23 & 7 & 0 & 0 \\
\hline & 22 & 7 & 1 & 1 \\
\hline
\end{tabular}


Learning Disability and Speech Disorder among Toddlers: A Case Study on Kurdish Pre-School Children, Areen Ahmed Muhammed

Table3. The Statements' Summation

Figure2. Interview Result

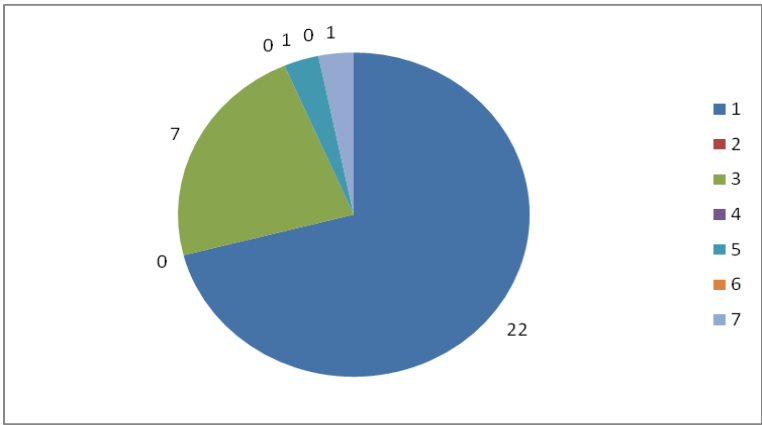

\begin{tabular}{|c|c|c|c|c|}
\hline 1 & 25 & 3 & 0 & 2 \\
\hline 2 & 3 & 18 & 7 & 2 \\
\hline 3 & 29 & 1 & 0 & 0 \\
\hline 4 & 22 & 7 & 1 & 0 \\
\hline 5 & 20 & 8 & 1 & 1 \\
\hline 6 & 21 & 5 & 2 & 2 \\
\hline 7 & 23 & 5 & 1 & 1 \\
\hline 8 & 22 & 8 & 0 & 0 \\
\hline 9 & 15 & 12 & 2 & 1 \\
\hline 10 & 23 & 7 & 0 & 0 \\
\hline & 20.3 & 7.4 & 1.4 & 0.9 \\
\hline
\end{tabular}

Table4. Statements' Result

Figure3. The Differentiation of the Data and the Procedure

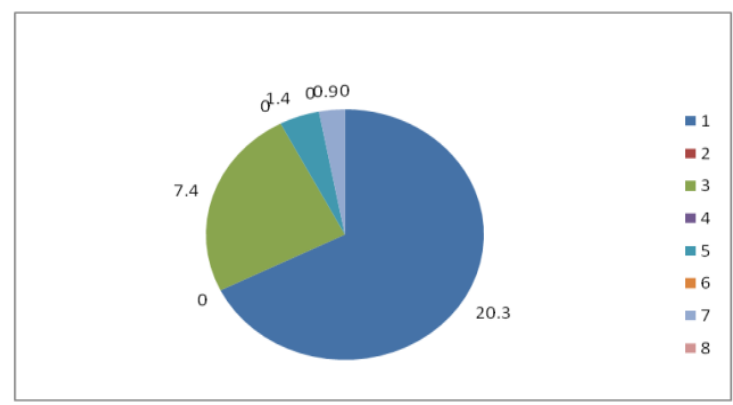

\section{Conclusion and Recommendation}

\subsection{Conclusion}

This research studied the impact of those reasons that have effects on children in learning a language, especially at an early age. It also shows the problems that children have when they learn to make conversation; moreover, it shows the disorders as they face through learning to talk. The findings of this study answered the research questions as this research intended to find out the problems and find solutions to those issues that infants have in learning to talk. The answer to the main research question; that is "The effect of parent's field whether employed parents or unemployed parents on toddlers" can be found through the findings as they illustrate that employed family talk more to their infants in comparison with unemployed parents. Furthermore, the teachers' finding is that unemployed parents talk less to their infants compared to the employed ones.

In addition, the second main research question, which is about "The benefits of telling the original names of items around toddlers", is answered through the data as well. The 
findings show that telling the original names by parents help the toddlers and infants to reduce their disorders, improve their pronunciation, and help them to learn the language sooner.

The answer to the last research question, which is about girls "Whether they learn sooner than boys in making conversation (talking), can be discussed also. According to the findings and collected data, both from the questionnaire and interview, it proves that the girl's ability to talk is better than the boy's. Regarding the findings of the study's validity, the research claims that reading story for toddlers by parents have a great impact on their ability to talk and it helps them to speak faster and sooner.

\subsection{Recommendations}

What is recommended for future researchers is to take care about the purpose behind each individual's learning style of a language; whether they want to learn just to pass exams or getting knowledge and communicate through that language, or they want to learn a language for the particular or decent job. Moreover, psychological, religious, family, and social barriers should be taken into consideration. Finally, individual differences should be accounted for, because as it is known that in all human beings' actions, individual differences play a vital role not just in learning a language but also in different scopes of life.

Many problems were encountered while writing this paper; the important ones will be time; as it was a great obstacle for the researcher, as he did not have enough spare time to search around for different primary schools due to university workload and all those nondepartmental subjects that he should have taught. In addition, regarding the interviews, the researcher had to ask many parents to convince them to participate in the interview as many of the parents were rejecting the idea when they were told that the interview would be recorded. Besides that, the researcher had to translate the interview into English-Kurdish because not all the participants could speak English. At last, three mothers were found who were willing to participate.

\section{References}

Bigner, J. (1979). A Tribute to the Founding Editor of the Journal of GLBT Family Studies. Journal of GLBT Family Studies, 7(5), 419-422.

Brown, H. Douglas. (2001). Teaching by Principle and Interactive Approach to Language Pedagogy. New York: Longman Inc.

Brown, R. (1973). A First Language: The Early Stages. Cambridge, MA: Harvard University Press.

Brumfit, C. J. (1980). From Denning to Designing: Communicative Specifications Versus Communicative Methodology in Foreign Language Teaching. Studies in Second Language Acquisition, 3(1), 1-9.

Brumfit, C. J. (1984). Communicative Methodology in Language Teaching. Cambridge: Cambridge University Press.

Bruner, J. (1983).In Search of Mind: Essays in Autobiography. New York, NY: Harper \& Row.

Bruner, J. (1996).The Culture of Education. Cambridge, MA: Harvard University Press.

Chomsky, N. (1994). Naturalism and Dualism in the Study of Language and Mind. International Journal of Philosophical Studies, 2, 181-209.

Clark, S. (2003). Enhancing the Educational Value of Business Internships. Journal of Management Education, 27(4), 472-484. 
Learning Disability and Speech Disorder among Toddlers: A Case Study on Kurdish Pre-School Children, Areen Ahmed Muhammed

Cohen, L., and Holliday, M. (1979). Statistics for Education and Physical Education. London: Harper \&Row.

Cohen, L., and Holliday, M. (1982). Statistics for Social Scientists. London: Harper \& Row.

Cohen, L., and Holliday, M. (1996). Practical Statistics for Students. London: Paul Chapman.

Cohen, L., and Manion, L. (1994). Research Methods in Education (4th Ed.). London: Routledge.

Cohen, L.; Manion, L.; and Morrison, K. R. B. (2004). A Guide to Teaching Practice (5th Ed.). London: Routledge.

Cohen, M. R., and Nagel, E. (1961). An Introduction to Logic and Scientific Method. London: Routledge \& Kegan Paul.

De Villiers, J. G. (2007). The Interface of Language and Theory of Mind. Lingua, 117, 18581878.

Dornyei, Z. (2007). Research Methods in Applied Linguistics. New York: Oxford University Press.

Douglas, J.W.B. (1964). The Home and the School. MacGibbon and Kee, London.

Edward, J. (2013). Learning to Talk: Home. The USA: The University of Wisconsin-Madison.

Hart, B., \& Riseley, T. R. (1995). Meaningful Differences in the Everyday Experience of Young American Children. Baltimore, MD: Paul H. Brookes Publishing Company.

Hutten, A. P. (1999). An Empirical Assessment of the Residual Income Valuation Model1. Journal of Accounting and Management, 26(1), 1-34.

Hutten, J. (1999). Bio Feedback for Depression. Journal of Neurotherapy, 3, 28-35.

Jusczyk, P., and Honne, W. (1996). Finding and Remembering Words: Some Beginnings by English Learning Infants. Current Directions in Psychological Science, 6(6), 170-174.

Levin, V., and Vevea, J. (1998). Fixed- and Random-Effects Models in Meta-Analysis. Psychological Methods, 3(4), 486-504.

McCashen, A. (2005). A Strengths Approach to supporting Early Mathematics Learning in Family Contexts. Australasian Journal of Early Childhood, 41(1), 45-53.

Morris, J. C. (1966). Future of Chlorination. Journal Awwa, 58(11), 1475-1482.

Ocher, R. (2008). Elemental Analysis and Characterization of Ochre Sources from Southern Arizona. Journal of Science, 35(3), 752-762.

Pinker, S. (1994).The Language Instinct. New York: William Morrow.

Pinker, S. (1999). Words and Rules: The Ingredients of Language. New York, NY: HarperCollins.

Richard Nordauist, H. (2013). But Subject Matter Content Knowledge Is Not Enough. Urban Education, 48(3), 347-349.

Risley, T. R. (1995). Meaningful Differences in the Everyday Experience of Young American Children. Baltimore, MD: Paul H. Brookes Publishing Company.

Schumaker, J., and Deshler, D. (2009). Adolescents with Learning Disabilities as Writers: Are We Selling Them Short? Learning Disabilities: Research and Practice, 24(2), 81-92.

Smith, C.G. (1968). The Emergence of the Middle East. Journal of Contemporary History, 3(3), 3-17.

Snowling, MJ.; Stothard, SE.; Clarke, P.; Bowyer-Crane, C.; Harrington, A.; Truelove, E.; and Hulme, C. (2010). York Assessment of Reading for Comprehension. GL Assessment; London.

Vevea, J. L. (1998). Fixed- and Random-Effects Models in Meta-Analysis. Psychological Methods, 3(4), 486-504. 